\title{
Preparation, Characterization, and Catalytic Property of a Cu(II) Complex with 2-Carboxybenzaldehyde-p- Toluenesulfonyl Hydrazone Ligand
}

\author{
Xi-Shi Tai ${ }^{1}$, Peng-Fei Li ${ }^{2}, \mathrm{Li}-\mathrm{Li} \mathrm{Liu}^{1 *}$ \\ ${ }^{1}$ College of Chemistry and Chemical Engineering, Weifang University, Weifang 261061, P.R. China \\ ${ }^{2}$ College of Chemical Engineering, Qingdao University of Science and Technology, Qingdao 266061, \\ P.R. China
}

Received: 16 th March 2017; Revised: 17th July 2017; Accepted: 18 th July 2017

Available online: 22nd January 2018; Published regularly: 2nd April 2018

\begin{abstract}
Metal-organic complex hybrid materials constructed from carboxylate ligands and hydrazone ligands have exhibited potential application in many fields. In order to enrich the applications of the metaiorganic complex materials, a new hydrazone ligand contains carboxylate group, 2carboxybenzaldehyde- $p$-toluenesulfonyl hydrazone (L1), and its $\mathrm{Cu}(\mathrm{II})$ complex (C2), have been prepared. The structure of L1 was determined by elemental analysis, IR spectra and single crystal X-ray diffraction, and the composition of $\mathrm{Cu}(\mathrm{II})$ complex (C2) has also been determined by elemental analysis, IR and UV spectra. The catalytic activity for $\mathrm{A}^{3}$ coupling reaction of benzaldehyde, piperidine, and phenylacetylene has been investigated. The results show that $\mathrm{Cu}(\mathrm{II})$ complex displays a $100 \%$ selectivity to the product of propargylamine during $\mathrm{A}^{3}$ coupling reaction and benzaldehyde conversions were $95.3,94.2$, and $93.4 \%$ at $120^{\circ} \mathrm{C}$ for $12 \mathrm{~h}$ in the first, second, and third reaction cycles, respectively. Copyright ( $) 2018$ BCREC Group. All rights reserved
\end{abstract}

Keywords: Hydrazone ligand; $\mathrm{Cu}(\mathrm{II})$ complex material; Catalyst preparation and characterization; Catalytic property

How to Cite: Tai, X.S., Li, P.F., Liu, L.L. (2018). Preparation, Characterization, and Catalytic Property of a $\mathrm{Cu}$ (II) Complex with 2-Carboxybenzaldehyde-p-Toluenesulfonyl Hydrazone Ligand. Bulletin of Chemical Reaction Engineering \& Catalysis, 13 (1): 7-13 (doi:10.9767/bcrec.13.1.1012.7-13)

Permalink/DOI: https://doi.org/10.9767/bcrec.13.1.1012.7-13

\section{Introduction}

Metal-organic complex hybrid materials constructed from carboxylate ligands, and hydrazone ligands have exhibited potential application in many fields. For example, they have been widely exploited for luminescence [1-4], antitumor [5-8], antibacterial [9-12], gas storage [13], as well as magnetic [14-17]. Meanwhile, metal complex materials have also been

* Corresponding Author.

E-mail: taixs@wfu.edu.cn (Tai, X.S.)

Telp.: +86-536-8785363; Fax.: +86-536-8785363 attracted interests due to their excellent catalytic activities for many organic reactions [18$22]$.

However, to the best of our knowledge, the studies on the three component coupling reaction ( $\mathrm{A}^{3}$ coupling) of aldehydes, alkynes and amines with $\mathrm{Cu}(\mathrm{II})$ complexes as catalysts are relatively few. Therefore, the investigation on catalytic activity for three component coupling reaction ( $\mathrm{A}^{3}$ coupling) of aldehydes, alkynes and amines with metal complexes as catalysts has been the goal of our research group [23-25]. 
Herein, in this paper, we have synthesized a new hydrazone ligand named 2 carboxybenzaldehyde- $p$-toluenesulfonyl hydrazone (L1), and its $\mathrm{Cu}(\mathrm{II})$ complex (C2). $\mathrm{Cu}(\mathrm{II})$ complex (C2) catalyst shows better catalytic activity for three component coupling reaction $\left(\mathrm{A}^{3}\right.$ coupling) of benzaldehyde, piperidine, and phenylacetylene with the benzaldehyde conversion reached $95.3 \%$. Interestingly, $\mathrm{Cu}(\mathrm{II})$ complex catalyst (C2) is very stable because the catalytic efficiency remained above $93.4 \%$ after four cycles. This study was significant for the further study of $\mathrm{Cu}$ (II) complex catalyst. The simple flow charts for synthesis procedure of $\mathbf{L} \mathbf{1}$ and $\mathbf{C} \mathbf{2}$ are shown in Figure 1.

\section{Materials and Method}

\subsection{Materials and measurements}

All chemical reagents were analytical grade. 2-Carboxybenzaldehyde, $p$-toluenesulfonyl hydrazine, $\mathrm{Cu}\left(\mathrm{CH}_{3} \mathrm{COO}\right)_{2} \cdot \mathrm{H}_{2} \mathrm{O}$, and $\mathrm{NaOH}$ were ordered from Xiya reagent, while phenylacetylene, piperidine, benzaldehyde, and 1,4-dioxane were ordered from Alfa Aesar. Elemental analyses $(\mathrm{C}, \mathrm{H}$, and $\mathrm{N})$ were analyzed on an Elementar Vario III EL Elemental Analyzer. IR spectra in the $4000-400 \mathrm{~cm}^{-1}$ region were carried out on a Nicolet AVATAR 360 infrared spectrometer. The crystal data of 2carboxybenzaldehyde- $p$-toluenesulfonyl hydrazone (L1) were collected by a Bruker Smart CCD diffractometer.

\subsection{Synthesis of 2-Carboxybenzaldehyde-p- toluenesulfonyl hydrazone (L1)}

The 2-Carboxybenzaldehyde $(0.1501 \mathrm{~g}, 1.0$ $\mathrm{mmol})$ in ethanol solution $(10 \mathrm{~mL})$ was added to the ethanol solution $(10 \mathrm{~mL})$ containing $p$ toluenesulfonyl hydrazine $(0.1862 \mathrm{~g}, 1.0 \mathrm{mmol})$. The mixture was refluxed for $6 \mathrm{~h}$ with stirring, and then cooled to room temperature. The crystals of 2-carboxybenzaldehyde-p- toluenesulfonyl hydrazone (L1) were obtained by slowly evaporating the filtrate at room temperature. Elemental analysis calculated for $\mathrm{C}_{15} \mathrm{H}_{14} \mathrm{~N}_{2} \mathrm{O}_{4} \mathrm{~S}$ (\%) were $\mathrm{C}, 56.54 ; \mathrm{H}, 4.40 ; \mathrm{N}$, 8.80. Found (\%): C, 56.36; H, 4.69; N, 8.91. The selected IR bands (KBr) were: $3439 \mathrm{~cm}^{-1}$ $(-\mathrm{NH}-), \quad 1762 \quad \mathrm{~cm}^{-1} \quad(-\mathrm{COO}-), \quad 1589 \quad \mathrm{~cm}^{-1}$ $(-\mathrm{C}=\mathrm{N}-)$, UV-vis: $278 \mathrm{~nm}$.

\subsection{Synthesis of $\mathrm{Cu}(\mathrm{II})$ complex (C2)}

The 2 -carboxybenzaldehyde- $p$ toluenesulfonyl hydrazone (L1) ligand (1.0 mmol, $0.3183 \mathrm{~g}$ ) and $\mathrm{NaOH}(1.0 \mathrm{mmol}, 0.040$ g) were dissolved in $10 \mathrm{~mL}$ ethanol/water (v:v = $2: 1)$ solution. The $\mathrm{Cu}\left(\mathrm{CH}_{3} \mathrm{COO}\right)_{2} \cdot \mathrm{H}_{2} \mathrm{O} \quad(0.5$ mmol, $0.0985 \mathrm{~g}$ ) was added to the above solution. Then the mixture was stirred at $60{ }^{\circ} \mathrm{C}$ for $7 \mathrm{~h}$. The blue precipitation of $\mathrm{Cu}$ (II) complex was collected by filtration, purified by washing three times with ethanol and dried for $12 \mathrm{~h}$ at $80^{\circ} \mathrm{C}$.

The elemental analyses of $\mathrm{C}, \mathrm{H}$, and $\mathrm{N}$ were 48.29, 4.40, 7.04 (Calc.), and 48.59, 4.19, 6.91 (Found). The selected IR bands (KBr) were: $3444 \mathrm{~cm}^{-1}\left(\mathrm{H}_{2} \mathrm{O}+-\mathrm{NH}-\right), 1776 \mathrm{~cm}^{-1}(-\mathrm{COO}-)$, $1594 \mathrm{~cm}^{-1}(-\mathrm{C}=\mathrm{N}-), 1394 \mathrm{~cm}^{-1}\left(\mathrm{CH}_{3} \mathrm{COO}-\right)$, UVvis: $315 \mathrm{~nm}$.

\subsection{X-ray crystallography}

The single crystal of 2-carboxybenzaldehyde- $p$-toluenesulfonyl hydrazone (L1) $(0.22$ $\mathrm{mm} \times 0.19 \mathrm{~mm} \times 0.18 \mathrm{~mm}$ ) was measured on a Bruker Smart CCD diffractometer with graphite-monochromatic $\mathrm{Mo}-\mathrm{K} a$ radiation $(\lambda=$ $0.71073 \AA$ ) at $293(2) \mathrm{K}$. The structure was solved by direct methods with SHELXS-97 [26] and refined by full-matrix least-squares techniques on $F^{2}$ with SHELXL-97 [27]. Absorption correction was carried out using semi-empirical methods from equivalents. Crystallographic data and refinement details of $\mathbf{L} \mathbf{1}$ are listed in Table 1.



Figure 1. The flow charts for synthesis procedure of $\mathbf{L} 1$ and $\mathbf{C 2}$ 


\subsection{General procedure for the three com- ponent coupling reaction $\left(\mathrm{A}^{3}\right)$}

The catalytic performance of $\mathrm{Cu}(\mathrm{II})$ complex was assessed in the three component coupling reactions $\left(\mathrm{A}^{3}\right)$ of benzaldehyde, phenylacetylene, and piperidine (Figure 2). In typical, the benzaldehyde $(0.13 \mathrm{mmol})$, phenylacetylene $(0.17 \mathrm{mmol})$, piperidine $(0.15 \mathrm{mmol}), \mathrm{Cu}(\mathrm{II})$ complex catalyst $(40 \mathrm{mg})$ and 1,4-dioxane (1.5 g) were put in a $8 \mathrm{~mL}$ a closed glass reactor $(8$ $\mathrm{mL}$, Synthware) and the mixture was extensively stirred (ca. $400 \mathrm{rpm}$ ) at $120^{\circ} \mathrm{C}$ for $12 \mathrm{~h}$. After completion of the reaction, the solid cata- lyst was removed from the solution by centrifugation at $14000 \mathrm{rpm}$ for 6 minutes. The product was analysed by GC ((GC-1100, capillary column SE-54) using $n$-nonane as the external standard. The conversion and selectivity were calculated by Equations (1) and (2), respectively.

$$
\begin{aligned}
& C_{\text {benzaldehyde }}=\frac{n_{\text {initial }}-n_{\text {after reaction }}}{n_{\text {initial }}} \times 100 \% \\
& S=\frac{n_{\text {proparg yla mine }}}{n_{\text {initial }}-n_{\text {after reaction }}} \times 100 \%
\end{aligned}
$$

Table 1. Crystallographic data and refinement details for $\mathbf{L 1}$

\begin{tabular}{ll}
\hline Empirical formula & $\mathrm{C}_{15} \mathrm{H}_{14} \mathrm{~N}_{2} \mathrm{O}_{4} \mathrm{~S}$ \\
Formula weight & 318.35 \\
Temperature/K & $293(2)$ \\
Crystal system & triclinic \\
Space group & $P-1$ \\
$a / \AA$ & $5.7518(12)$ \\
$b / \AA$ & $10.677(2)$ \\
$c / \AA$ & $11.975(2)$ \\
$a /^{\circ}$ & $95.80(3)$ \\
$\beta /^{\circ}$ & $93.60(3)$ \\
$\gamma^{\circ}$ & $95.02(3)$ \\
Volume/Å & $726.9(2)$ \\
$Z$ & 2 \\
$\rho_{\text {calcmg/mm }}{ }^{3}$ & 1.454 \\
$\mu /$ mm $^{-1}$ & 0.243 \\
$S$ & 1.09 \\
$F(000)$ & 332 \\
Index ranges & $-6 \leq h \leq 5 ;-12 \leq k \leq 12 ;-14 \leq l \leq 14$ \\
Reflections collected & 5648 \\
Independent reflections & $2552[R(\mathrm{int})=0.0321]$ \\
Data/restraints/parameters & $2552 / 0 / 201$ \\
Goodness-of-fit on $F{ }^{2}$ & 1.085 \\
Final $R$ indexes $[I \geq 2 \sigma(I)]$ & $R_{1}=0.0489, w R_{2}=0.1208$ \\
Final $R$ indexes [all data] & $R_{1}=0.0563, w R_{2}=0.1269$ \\
Largest diff. peak and hole & 0.474 and $-0.320 \mathrm{e} \cdot \AA^{-3}$ \\
\hline &
\end{tabular}<smiles>CC#Cc1ccccc1CCN1CCCCC1</smiles>

Figure 2. The coupling of benzaldehyde, piperidine and phenylacetylene with 1,4-dioxane as solvent using $\mathrm{Cu}(\mathrm{II})$ complex as a catalyst 
The recovered catalyst was washed with 1,4dioxane $(3 \times 10 \mathrm{~mL})$, dried under vacuum at 50 ${ }^{\circ} \mathrm{C}$ for $6 \mathrm{~h}$, and stored for another consecutive reaction run.

\section{Results and Discussion}

\subsection{FTIR Spectra of Cu(II) complex (C2)}

The IR spectrum of $\mathrm{Cu}$ (II) complex (C2) is given in Figure 3. The strong absorption band at $3444 \mathrm{~cm}^{-1}$ in the IR spectrum of $\mathrm{Cu}(\mathrm{II}) \mathrm{com}$ plex (C2) can be assigned to the vibration peaks of $-\mathrm{NH}-$ and $-\mathrm{OH}$, which show that the $\mathrm{Cu}(\mathrm{II})$ complex (C2) containing $\mathrm{H}_{2} \mathrm{O}$. The weak vibration peak of $-\mathrm{COO}-$ at $1776 \mathrm{~cm}^{-1}$ shows that the oxygen atom of $-\mathrm{COO}-$ coordinates to $\mathrm{Cu}(\mathrm{II})$. The characteristic band of $-\mathrm{C}=\mathrm{N}-$ appears at $1594 \mathrm{~cm}^{-1}$, which indicates that the $\mathrm{N}$ atom of $-\mathrm{C}=\mathrm{N}-$ does not coordinate to the $\mathrm{Cu}(\mathrm{II})$ ion. The strong vibration peak at 1394 $\mathrm{cm}^{-1}$ shows that the $\mathrm{Cu}(\mathrm{II})$ complex (C2) containing $\mathrm{CH}_{3} \mathrm{COO}$, which is consistent with the results of elemental analysis [28].

\subsection{Structural description of 2-carboxy- benzaldehyde-p-toluenesulfonyl hydra- zone (L1)}

The molecular structure of $\mathbf{L} \mathbf{1}$ ligand is

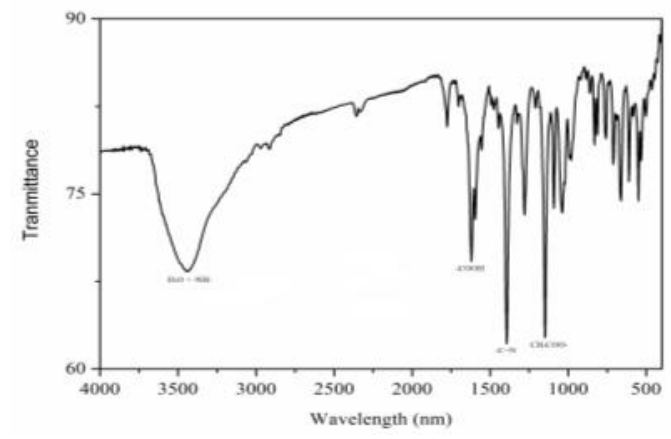

Figure 3. The IR spectra of $\mathrm{Cu}(\mathrm{II})$ complex (C2)

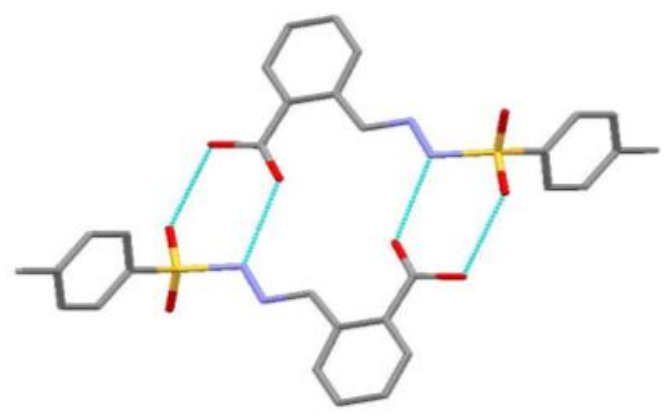

Figure 5. The H-Bonds interaction in L1 ligand given in Figure 4. The selected bond lengths and bond angles were listed in Table 2. Single crystal analysis reveals that the $\mathbf{L} \mathbf{1}$ ligand crystallizes in triclinic $P$ - 1 space group. The dihedral angle is $81.8^{\circ}$ between the plane 1 (C1C2-C3-C4-C5-C6) and the plane 2 (C9-C10C11-C12-C13-C14), which showing that the L1 ligand is not coplanar. The bond length of C8N2 is $1.274(3) \AA$, which is consistent with those hydrazone compounds reported in the other Ref. [29], and indicating that C8-N2 bond is double bond. Two L1 molecules form dimeric through $\mathrm{O}-\mathrm{H} \cdots \mathrm{O}$ and $\mathrm{N}-\mathrm{H} \cdots \mathrm{O}$ hydrogen bonds (Figure 5). Furthermore, the dimeric forms a one-dimensional chain structure by the interaction of $\Pi-\Pi$ stacking (Figure 6).

\subsection{Catalytic studies}

The catalytic performance of $\mathrm{C} 2$ was assessed in the $\mathrm{A}^{3}$ coupling reaction of benzaldehyde, phenylacetylene, and piperidine in a 1:1.2:1.3 mole ratio with 1,4-dioxane as a solvent at $120^{\circ} \mathrm{C}$. The results of catalytic activity are summarized in Table 3. The C2 exhibited good catalytic activity in the $\mathrm{A}^{3}$ reaction of benzaldehyde, phenylacetylene, and piperidine at $120{ }^{\circ} \mathrm{C}$ with 1,4 -dioxane as solvent. The conversion of benzaldehyde is $95.2 \%$ at $120{ }^{\circ} \mathrm{C}$ for 12 $\mathrm{h}$ over $\mathrm{C} 2$. The $\mathrm{C} 2$ could be recycled at least

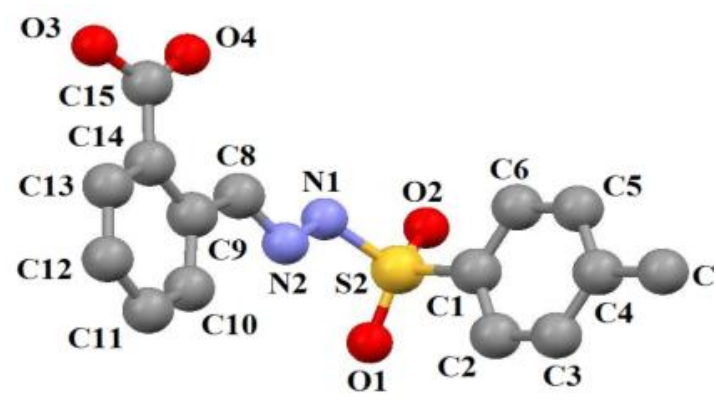

Figure 4. The molecular structure of L1 ligand



Figure 6. 1D chained structure by the interaction of H-Bonds and $\Pi-\Pi$ stacking 
three times, and the catalytic activity decreased slightly. The benzaldehyde conversions were $95.3,94.2$, and $93.4 \%$ at $120^{\circ} \mathrm{C}$ within 12 $\mathrm{h}$ in the first, second, and third reaction cycles, respectively.

The coordinative unsaturated metal site of $\mathrm{Cu}$ (II) of $\mathrm{C} 2$ has high stability in the processing of $\mathrm{A}^{3}$ coupling reaction. This could be the reason for the catalyst $\mathrm{C} 2$ can be reused at least three times with slight decreased in conversion of benzaldehyde. The $\mathrm{C} 2$ displays $100 \%$ selectivity to the product of propargylamines during $\mathrm{A}^{3}$ coupling reaction. Borah et al. [30] reported that the yield of propargylamines was $94 \%$ over $\mathrm{Cu}^{0}$ nanoparticles catalyst with toluene as solvent at $110^{\circ} \mathrm{C}$ for $3 \mathrm{~h} \mathrm{[30],} \mathrm{however,} \mathrm{the} \mathrm{ac-}$ tivity of the catalysts decreased in the successive reuse, the yields were $90 \%$ and $88 \%$ in the second and third cycles. Liu et al. [31] reported that the yield of propargylamine reached $97.9 \%$ for $5 \mathrm{~h}$ over Au/MIL-53(Al) [31], however, the leaching of gold was unavoidable for the first reuse. The $\mathrm{NH}_{2}-\mathrm{MIL}-53(\mathrm{Al})$ supported $\mathrm{Au}^{3+} / \mathrm{Au}^{0}$ gave $58.6 \%$ yield of propargylamine at $120^{\circ} \mathrm{C}$ for $4 \mathrm{~h}$ [32]. Copper nanoparticles supported on starch micro particles $(\mathrm{CuNPs} @ \mathrm{MS})$ gave a yield of $30 \%$ within $20 \mathrm{~h}$ at $60{ }^{\circ} \mathrm{C}$ for the $\mathrm{A}^{3}$ coupling reaction of benzaldehyde, phenylacetylene, and piperidine in 1,4-dioxane [33]. Although the $\mathrm{C} 2$ shows the similar yields/conversions with the catalysts of $\mathrm{Cu}^{0}$ nanoparticles catalyst and Au/MIL-53(Al), the $\mathrm{C} 2$ catalyst shows higher catalytic activity than $\mathrm{Au}^{3+} / \mathrm{Au}^{0}$ supported on $\mathrm{NH}_{2}-\mathrm{MIL}-53(\mathrm{Al})$ and copper nanoparticles supported on starch micro particles.

\section{Conclusions}

In summary, a new hydrazone ligand, 2carboxybenzaldehyde- $p$-toluenesulfonyl hydrazone (L1), and its $\mathrm{Cu}$ (II) complex (C2), have been prepared and characterized. The $\mathrm{Cu}(\mathrm{II})$ complex (C2) catalyst shows better catalytic activity for three component coupling reaction $\left(\mathrm{A}^{3}\right.$ coupling) of benzaldehyde, piperidine, and phenylacetylene with the benzaldehyde conversion reached $95.3 \%$. Furthermore, the catalytic

Table 2. The selected $t$ bond parameters of $\mathbf{L 1}$

\begin{tabular}{cccc}
\hline Bond & Distance $(\AA)$ & Angle & $\left({ }^{\circ}\right)$ \\
\hline $\mathrm{S} 2-\mathrm{O} 1$ & $1.4215(17)$ & O1-S2-O2 & $119.43(11)$ \\
$\mathrm{S} 2-\mathrm{O} 2$ & $1.4400(17)$ & O1-S2-N1 & $109.84(11)$ \\
$\mathrm{S} 2-\mathrm{N} 1$ & $1.6175(19)$ & O2-S2-N1 & $102.82(10)$ \\
$\mathrm{S} 2-\mathrm{C} 1$ & $1.762(2)$ & O1-S2-C1 & $108.06(11)$ \\
$\mathrm{N} 2-\mathrm{C} 8$ & $1.274(3)$ & $\mathrm{C} 1-\mathrm{S} 2-\mathrm{O} 2$ & $108.36(11)$ \\
$\mathrm{N} 1-\mathrm{N} 2$ & $1.386(2)$ & $\mathrm{N} 1-\mathrm{S} 2-\mathrm{C} 1$ & $107.77(11)$ \\
$\mathrm{C} 15-\mathrm{O} 4$ & $1.196(3)$ & N1-N2-C8 & $114.38(18)$ \\
$\mathrm{C} 15-\mathrm{O} 3$ & $1.324(3)$ & N2-N1-S2 & $117.12(14)$ \\
& & O3-C15-O3 & $121.0(2)$ \\
& & O4-C15-C14 & $125.8(2)$ \\
& & O3-C15-C14 & $113.26(19)$ \\
\hline
\end{tabular}

Table 3. Coupling of benzaldehyde, phenylacetylene, and piperidine catalyzed by $\mathrm{Cu}$ (II) complex in 1,4-dioxane ${ }^{\mathrm{a}}$

\begin{tabular}{ccccc}
\hline Entry & Solvent & Temperature $\left({ }^{\circ} \mathrm{C}\right)$ & Time $(\mathrm{h})$ & Conversion $(\%)^{\mathrm{b}}$ \\
\hline Fresh & 1,4-dioxane & 120 & 12 & $95.2 \%$ \\
Run 1 & 1,4-dioxane & 120 & 12 & $95.3 \%$ \\
Run 2 & 1,4-dioxane & 120 & 12 & $94.2 \%$ \\
Run 3 & 1,4-dioxane & 120 & 12 & $93.4 \%$ \\
\hline
\end{tabular}

aReaction conditions: aldehyde $(0.13 \mathrm{mmol})$, amine $(0.17 \mathrm{mmol})$, alkyne $(0.15 \mathrm{mmol}), \mathrm{Cu}(\mathrm{II})$ complex $(40$ $\mathrm{mg})$, dioxane $(1.500 \mathrm{~g})$.

bThe products was determined by GC analysis of the samples (GC-1100, capillary column SE-54) using nnonane as the external standard. 
activity imply $\mathrm{Cu}(\mathrm{II})$ complex catalyst (C2) may be a good candidate for catalytic material.

\section{Acknowledgement}

This project was supported by the National Natural Science Foundation of China (No. 21171132), the Natural Science Foundation of Shandong (ZR2014BL003), the project of Shandong Province Higher Educational Science and Technology Program (J14LC01) and Science Foundation of Weifang.

\section{References}

[1] Ajlouni, A.M., Abu-Salem, Q., Taha, Z.A., Hijazi, A.K., Momani, W.A. (2016). Synthesis, Characterization, Biological Activities and Luminescent Properties of Lanthanide Complexes with [2-Thiophenecarboxylic Acid, 2-(2-Pyridinylmethylene)hydrazide] Schiff Bases Ligand. Journal of Rare Earths, 34: 986-993.

[2] Wang, Q., Fan, Y., Song, T.Y., Xu, J.N., Wang, J., Chai, J., Liu, Y.L., Wang, L., Zhang, L.R. (2015). In Situ Synthesis of A Series of Lanthanide Coordination Polymers Based on N-heterocyclic Carboxylate Ligands: Crystal Structure and Luminescence. Inorganica Chimica Acta, 438: 128-134.

[3] Song, J., Wang, J.J., Hu, H.M., Wu, Q.R., Xie, J., Dong, F.X., Yang, M.L., Xue, G.L. (2014). Syntheses, Structures and Properties of Four 3D Microporous Lanthanide Coordination Polymers Based on 3,5-Pyrazoledicarboxylate and Oxalate Ligands. Journal of Solid State Chemistry, 212: 185-190.

[4] Yang, Y.Q., Yang, J., Kan, W.Q., Yang, Y., Guo, J., Ma, J.F. (2013). A Series of 1D, 2D, and 3D Coordination Polymers Based on Flexible 3-Carboxy-1-Carboxymethyl-2Oxidopyridinium and Different N-Donor Ligands - Syntheses, Structures, and Luminescent Properties. European Journal of Inorganic Chemistry, 2013: 280-292.

[5] Solanki, A., Sadhu, M.H., Patel, S., Devkar, R., Kumar, S.B. (2015). Ternary Complexes of Copper(II) and Cobalt(II) Carboxylate with Pyrazole Based Ligand: Syntheses, Characterization, Structures, and Bioactivities. Polyhedron, 102: 267-275.

[6] Vanicek, S., Kopacka, H., Wurst, K., Vergeiner, S., Oehninger, L., Ott, I., Bildstein, B. (2015). Cobaltocenium Carboxylate Transition Metal Complexes: Synthesis, Structure, Reactivity, and Cytotoxicity. Zeitschrift für Anorganische und Allgemeine Chemie, 641: 1282-1292.
[7] Xu, J., Zhou, T., Xu, Z.Q., Gu, X.N., Wu, W.N., Chen, H., Wang, Y., Jia, L., Zhu, T.F., Chen, R.H. (2017). Synthesis, Crystal Structures and Antitumor Activities of Copper(II) Complexes with A 2 Acetylpyrazine Isonicotinoyl Hydrazone Ligand. Journal of Molecular Structure, 1128: 448-454.

[8] Ferreira, I.P., Piló, Elisa, D.L., RecioDespaigne, A.A., Da Silva, J.G., Ramos, J.P., Marques, L.B., Prazeres, P.H.D.M., Takahashi, J.A., Souza-Fagundes, E.M., Rocha, W., Beraldo, H. (2016). Bismuth(III) Complexes with 2-Acetylpyridine- and 2Benzoylpyridine-derived Hydrazones: Antimicrobial and Cytotoxic Activities and Effects on the Clonogenic Survival of Human Solid Tumor Cells. Bioorganic \& Medicinal Chemistry, 24: 2988-2998.

[9] Hijazi, A.K., Taha, Z.A., Ajlouni, A.M., AlMomani, W.M., Idris, I.M., Hamra, E.A. (2017). Synthesis and Biological Activities of Lanthanide (III) Nitrate Complexes with N(2-hydroxynaphthalen-1-yl) methylene) Nicotinohydrazide Schiff Base. Medicinal Chemistry, 13: 77-84.

[10] Wang, J., Qu, D., Lei, J.X., You, Z.L. (2017). Synthesis, Crystal Structures and Jack Bean Urease Inhibitory Activity of Copper(II) Complexes with 4-Bromo-N'-(2-hydroxy-5methoxybenzylidene)benzohydrazide. Journal of Coordination Chemistry, 70: 544-555.

[11] Zafarian, H., Sedaghat, T., Motamedi, H., Rudbari, H.A. (2016). A Multiprotic Ditopic Thiocarbohydrazone Ligand in the Formation of Mono- and Di-nuclear Organotin(IV) Complexes: Crystal Structure, Antibacterial Activity and DNA Cleavage. Journal of Organometallic Chemistry, 825-826: 25-32.

[12] Kehinde, O., Joseph, A., Tolutope, S., Olanrewaju, A., Christiana, A., Kayode, A., Salih, M.S., Tadigoppula, N. (2016). Synthesis, Characterization, Theoretical Treatmentand Antitubercular Activity Evaluation of $(E)-N^{\prime}-(2,5-$ Dimethoxylbenzylidene) nicotinohydrazide and Some of Its Transition Metal Complexes Against Mycobacterium Tuberculosis, H37Rv. Oriental Journal of Chemistry, 32: 413-427.

[13] Kornel, R., Irena, S., Stefan, K., Dariusz, M. (2016). Carboxylate-Hydrazone Mixed-Linker Metal-Organic Frameworks: Synthesis, Structure, and Selective Gas Adsorption. European Journal of Inorganic Chemistry, 2016: 4450-4456.

[14] Wen, H.R., Dong, P.P., Liang, F.Y., Liu, S.J., Xie, X.R., Tang, Y.Z. (2017). A Family of 2D Lanthanide Complexes Based on Flexible 
Thiodiacetic Acid with Magnetocaloric or Ferromagnetic Properties. Inorganica Chimica Acta, 455: 190-196.

[15] Xu, J.Q., Zheng, Y.Q., Xu, W. (2017). Synthesis, Crystal Structures, and Properties of Copper(II) Dicarboxylate Complexes with [Bis(2-pyridylcarbonyl)amido]. Russian Journal of Coordination Chemistry, 43: 63-72.

[16] Tai, X.S., Meng, Q.G., Liu, L.L. (2016). Synthesis, Crystal Structure and Spectroscopic Analysis of a New Sodium Coordination Polymer. Open Chemistry, 14: 274-278.

[17] Sadhu, M.H., Mathoniere, C., Patil, Y.P., Kumar, S.B. (2017). Binuclear Copper(II) Complexes with $\mathrm{N}_{3} \mathrm{~S}$-coordinate Tripodal Ligand and Mixed Azide-carboxylate Bridges: Synthesis, Crystal Structures and Magnetic Properties. Polyhedron, 122: 210-218.

[18] Miriam, N.G., Kohsuke, M., Ai, N., Yasutaka, K., Hiromi, Y. (2016). Highly Efficient $\mathrm{Ru} /$ carbon Catalysts Prepared by Pyrolysis of Supported $\mathrm{Ru}$ Complex Towards the Hydrogen Production from Ammonia Borane. Applied Catalysis A: General, 527: 45-52.

[19] Yang, D., Odoh, S.O., Borycz, J., Wang, T.C., Farha, O.K., Hupp, J.T., Cramer, C.J., Gagliardi, L., Gates, B.C. (2016). Tuning $\mathrm{Zr}_{6}$ Metal-Organic Framework (MOF) Nodes as Catalyst Supports: Site Densities and Electron-Donor Properties Influence Molecular Iridium Complexes as Ethylene Conversion Catalysts. ACS Catalysis, 6: 235247.

[20] Thangavel, S., Boopathi, S., Mahadevaiah, N., Kolandaivel, P., Pansuriya, P.B., Friedrich, H.B. (2016). Catalytic Oxidation of Primary aromatic alcohols Using Half Sandwich Ir(III), Rh(III) and Ru(II) Complexes: A Practical and Theoretical Study. Journal of Molecular Catalysis A: Chemical, 423: 160171.

[21] Gao, R., Zhang, M., Liang, T.L., Wang, F.S., Sun, W.H. (2008). Nickel(II) Complexes Chelated by 2-Arylimino-6benzoxazolylpyridine: Syntheses, Characterization, and Ethylene Oligomerization. Organometallics, 27: 5641-5648.

[22] Saka, E.T., Sark, G., Kantekin, H., Koca, A. (2016). Electrochemical, Spectroelectrochemical and Catalytical Properties of New $\mathrm{Cu}(\mathrm{II})$ and $\mathrm{Co}(\mathrm{II})$ Phthalocyanines. Synthetic Metals, 214: 82-91.

[23] Tai, X.S., Liu, L.L., Yin, J. (2014). Synthesis, Crystal Structure of Tetra-Nuclear Macrocyclic $\mathrm{Cu}(\mathrm{II})$ Complex Material and Its Application as Catalysts for $\mathrm{A}^{3}$ Coupling
Reaction. Journal of Inorganic and Organometallic Polymers and Materials, 24(6): 1014-1020.

[24] Tai, X.S., Liu, L.L. (2015). Synthesis, Crystal Structure of a $\mathrm{Mg}$ (II) Complex Materials and Its Application as Catalysts for $\mathrm{A}^{3}$ Coupling Reaction. The Open Materials Science Journal, 9: 1-5.

[25] Wang, L.H., Liang, L., Wang, X. (2017). Synthesis, Structural Characterization, and Catalytic Activity of $\mathrm{A} \mathrm{Cu}$ (II) Coordination Polymer Constructed From 1,4Phenylenediacetic Acid and 2,2'-Bipyridine. Bulletin of Chemical Reaction Engineering \& Catalysis, 12: 113-118.

[26] Sheldrick, G.M. (1997). SHELXL-97, Program for Crystal Structure Solution. University of Göttingen: Göttingen, Germany.

[27] Sheldrick, G.M. (1997). SHELXTL-97, Program for Crystal Structure Refinement. University of Göttingen: Göttingen, Germany.

[28] Nakamoto, K. (1978). Infrared and Ramen Spectra of Inorganic and Coordination Compounds. $3^{\text {rd }}$ ed.; John Wiley and Sons: New York, NY, USA, Volume 1, pp. 359-368.

[29] Wang, L.H., Tai, X.S. (2016). The Synthesis and Crystal Structure of Two New Hydrazone Compounds. Crystals, 6: 57

[30] Borah, B.J., Borah, S.J., Saikia, L., Dutta, D.K. (2014). Efficient Three-component Coupling Reactions Catalyzed by $\mathrm{Cu}^{0}$ nanoparticles Stabilized on Modified Montmorillonite. Catal. Sci. Technol., 4: 1047-1054.

[31] Liu, L.L., Tai, X.S., Zhang, N.N., Meng, Q.G., Xin, C.L. (2016). Supported Au/MIL-53(Al): a reusable green solid catalyst for the threecomponent coupling reaction of aldehyde, alkyne, and amine. Reac. Kinet. Mech. Catal., 119: 335-348.

[32] Liu, L.L., Tai, X.S., Zhou, X.J., Liu, L.J. (2017). Synthesis, Post-modification and Catalytic Properties of Metal-organic Framework NH2-MIL-53(Al). Chem. Res. Chinese University, 33(2): 231-238.

[33] Gholinejad, M., Saadati, F., Shaybanizadeh, S., Pullithadathil, B. (2016). Copper Nanoparticles Supported on Starch Micro Particles as A Degradable Heterogeneous Catalyst for Three-component Coupling Synthesis of Propargylamines. RSC Advances. 6: 4983-4991. 